\title{
Phosphatidylserine exposure during apoptosis reflects bidirectional trafficking between plasma membrane and cytoplasm
}

\author{
S-H Lee ${ }^{1,2}, \mathrm{XW}$ Meng ${ }^{1,2}, \mathrm{KS} \mathrm{Flatten}^{2}$, DA Loegering ${ }^{2}$ and SH Kaufmann ${ }^{\star, 1,2}$
}

Phosphatidylserine (PS) exposure on the external leaflet of the plasma membrane is widely observed during apoptosis and forms the basis for the annexin V binding assay to detect apoptotic cell death. Current efforts to explain PS exposure focus on two potential mechanisms, activation of a phospholipid scramblase or calcium-mediated trafficking of lysosomes to the cell surface. Here, we provide evidence that apoptotic PS exposure instead reflects bidirectional trafficking of membrane between the cell surface and cytoplasm. Using a series of cell lines, some of which expose large amounts of PS during apoptosis and some of which do not, we demonstrate that accumulation of plasma membrane-derived cytoplasmic vesicles in a dynamin-, clathrin- and Cdc42-independent manner is a previously undescribed but widely occurring feature of apoptosis. The apoptotic exposure of PS occurs when these vesicles traffic back to cell surface in a calcium-dependent process that is deficient in a substantial fraction of human cancer cell lines. These observations provide a new model for PS externalization during apoptosis and simultaneously identify an altered step that accounts for the paucity of apoptotic PS exposure in many cell lines.

Cell Death and Differentiation (2013) 20, 64-76; doi:10.1038/cdd.2012.93; published online 3 August 2012

A common feature of apoptosis from Caenorhabditis elegans to man is the transfer of phosphatidylserine (PS) and phosphatidylethanolamine, which ordinarily reside on the cytoplasmic surface of the membranes, to the cell surface. ${ }^{1-4}$ The PS that is externalized not only contributes to the recognition and subsequent removal of apoptotic bodies by phagocytes, ${ }^{1,5,6}$ but also provides a binding site for the anionic lipid binding protein annexin $\mathrm{V},{ }^{7}$ which is widely used to detect apoptotic cells. ${ }^{8}$ In addition to its use in laboratory studies in vitro, annexin $\mathrm{V}$ binding is being explored as a potential early marker of treatment efficacy in cancer patients. ${ }^{9}$

The biochemical basis for apoptotic PS externalization remains incompletely understood. The most widely accepted model suggests that an enzyme capable of randomizing PS across the plasma membrane - a so-called scramblase - is activated during apoptosis. Consistent with this model, a polypeptide capable of scrambling PS in liposomes in vitro was purified; and the cDNA encoding this phospholipid scramblase (PLSCR1) was cloned. ${ }^{10}$ Plscr1 deletion in mice, however, had no effect on apoptosis-induced PS externalization. ${ }^{11}$ Additional studies suggested a role for the ATP-binding cassette (ABC) transporters $\mathrm{ABC} 1^{12}$ and $\mathrm{Tat}^{-1} 1^{4}$ in $\mathrm{PS}$ externalization, although the latter claim has also been questioned. ${ }^{13}$ More recently, TMEM16F was implicated in
$\mathrm{Ca}^{2+}$-dependent phospholipid scrambling in blood cells, ${ }^{14}$ although its role in apoptotic PS exposure has not been confirmed.

An alternative model suggests that apoptotic PS externalization reflects trafficking of lysosomes to the cell surface rather than a simple enzymological process. ${ }^{15}$ The demonstration that annexin $\mathrm{V}$ binding to staurosporine-treated HeLa cells could be inhibited by the lysosomotropic agent chloroquine, coupled with studies of NBD-PS dynamics, suggested that PS externalization reflects $\mathrm{Ca}^{2+}$-induced trafficking of lysosomes to the plasma membrane ${ }^{15}$ Whether this occurs in response to other stimuli and in different cells remains uncertain.

Despite the widespread use of PS externalization as a marker for apoptosis, certain cell lines undergo apoptosis with very little increase in annexin $\mathrm{V}$ binding. ${ }^{16}$ Although special assay conditions have been developed to detect PS on the surface of these apoptotic cells, ${ }^{8}$ the biological basis for the diminished PS externalization is unclear.

Based on the results of the present study, we propose a different mechanism for PS externalization during apoptosis. We also report that the second step in this process is impaired in a number of human cancer cell lines, providing an explanation for the low PS externalization observed during apoptosis in those lines.

\footnotetext{
${ }^{1}$ Department of Molecular Pharmacology and Experimental Therapeutics, Mayo Clinic College of Medicine, Rochester, MN 55905, USA and ${ }^{2}$ Department of Oncology, Mayo Clinic College of Medicine, Rochester, MN 55905, USA

*Corresponding author: SH Kaufmann, Division of Oncology Research, Mayo Clinic, Gonda 19-212, 200 First Street, SW, Rochester, MN 55905, USA. Tel: + 507 284 8950; Fax: + 507293 0107; E-mail: Kaufmann.scott@mayo.edu

Keywords: Annexin V; phosphatidylserine; membrane vesicles

Abbreviations: PS, phosphatidylserine; ABC, ATP-binding cassette; APC, allophycocyanin; CHX, cycloheximide; EBFP, enhanced blue fluorescent protein; EGFP, enhanced green fluorescent protein; FBS, heat-inactivated fetal bovine serum; FITC, fluorescein isothiocyanate; PLSCR1, phospholipid scramblase 1; PBS, calciumand magnesium-free Dulbecco's phosphate-buffered saline; PCR, polymerase chain reaction; Q-VD-OPh, N-(2-quinolyl)valylaspartyl-(2,6-difluorophenoxy)methyl ketone; TRAIL, tumor necrosis factor- $\alpha$-related apoptosis inducing ligand

Received 16.3.12; revised 25.6.12; accepted 26.6.12; Edited by G Melino; published online 03.8.12
} 


\section{Results}

Limited annexin V binding to apoptotic T98G, Daudi and D32 cells. To identify models for studying PS externalization, we searched for human cell lines with diminished annexin $\mathrm{V}$ binding during apoptosis. While studying TRAILinduced cell death in T98G glioblastoma cells (Figures 1a-e), ${ }^{17}$ we readily detected apoptotic changes when cells were assayed for nuclear fragmentation, extractable chromatin or cleavage of procaspases and caspase substrates. Nonetheless, these cells did not bind annexin V (Figures 1c and e) when the assay was performed using standard procedures. ${ }^{18}$ A similar discrepancy between annexin $\mathrm{V}$ binding and other assays for apoptosis was observed in T98G cells treated with etoposide (Supplementary Figure S1), Daudi cells exposed to camptothecin (Supplementary Figures S2a-e), and D32 cells incubated with TRAIL (Supplementary Figures S2g-i).

We initially examined the possibility that PS was not detected on these apoptotic cells because of problems with the annexin $\mathrm{V}$ binding assay. It has been suggested that annexin $\mathrm{V}$ binding can be missed if the assay is performed at high cell density. ${ }^{8}$ For subsequent studies, Jurkat cells, which stain strongly with annexin $\mathrm{V}^{3,17}$ and T98G cells were analyzed at the same time. Flow cytometer photomultipliers were set so that nonapoptotic Jurkat cells exhibited a very low annexin $\mathrm{V}$ signal (Figure 1f, lower left panel) and binding to the two lines was directly compared. Untreated T98G cells exhibited a mean fluorescence intensity that was $3.2 \pm 0.7$ fold higher (mean \pm S.D., $n=6$ ) than untreated Jurkat cells (Figure 1f, upper left panel), reflecting the larger volume of T98G cells (2100 versus $800 \mu \mathrm{m}^{3}$, respectively). When TRAIL-treated T98G cells at varying cell concentrations were stained with annexin $\mathrm{V}$, decreasing the cell concentration below that used in earlier studies ${ }^{2,3}$ resulted in increased annexin $\mathrm{V}$ staining (Figure $1 \mathrm{~g}$ ). Nonetheless, the TRAILinduced increase in annexin $\mathrm{V}$ binding at each cell concentration was much higher in apoptotic Jurkat cells, suggesting that T98G cells have a limitation in PS exposure that is not explained solely by use of the nonsaturating amounts of annexin $\mathrm{V}$ provided in commercial kits.

Cells with diminished apoptotic PS exposure contain anionic phospholipids, express putative scramblases and lack detectable scramblase inhibitors. To rule out the possibility that T98G cells lack aminophospholipids, cells were incubated with streptolysin $O$, then stained with annexin $\mathrm{V}$ and propidium iodide (PI). Cells that were permeabilized (as indicated by $\mathrm{PI}$ positivity) readily stained with annexin $\mathrm{V}$ (Supplementary Figure S3a, right panel, upper right quadrant). Likewise, T98G cells that were spontaneously permeabilized (Figure 1f, circled regions) bound at least as much annexin $\mathrm{V}$ as similarly permeabilized Jurkat cells.

To determine whether diminished annexin $\mathrm{V}$ binding might reflect a scramblase deficiency, expression of putative scramblase genes was assessed. PLSCR1 was expressed in T98G cells at the mRNA as well as the protein level (Supplementary Figures S3b and c). Sequencing of PLSCR1 cDNA failed to identify any mutations. In further experiments examining multiple cell lines, some of which bind annexin $\mathrm{V}$ extensively during apoptosis in our studies (Jurkat, HL-60,
K562) ${ }^{17,19}$ and some of which do not (T98G, D32, Daudi), there was no correlation between annexin $\mathrm{V}$ binding and expression of PLSCR1 or any other PLSCR family member (Supplementary Figures S3b and c). Likewise, there was no correlation between apoptotic annexin $\mathrm{V}$ binding and $\mathrm{mRNA}$ encoding ATP8A1, the closest human homolog of the Tat-1 gene implicated in $C$. elegans apoptotic PS externalization, ${ }^{4}$ or other members of this ATPase family (Supplementary Figure S3d). Moreover, TMEM16F, the enzyme recently implicated in $\mathrm{Ca}^{2+}$-dependent phospholipid scrambling in blood cells, ${ }^{14}$ was expressed in all of the lines (Supplementary Figure S3d) and did not lack exon 13, which was reported as a causative mutation in Scott Syndrome.

To address the possibility that T98G cells express a scramblase inhibitor, enhanced green fluorescent protein (EGFP)-labeled Jurkat cells were fused with enhanced blue fluorescent protein (EBFP)-labeled T98G cells, treated with ionomycin, stained with annexin $\mathrm{V}$ and $\mathrm{PI}$, and analyzed. If T98G cells contained a scramblase inhibitor, fused cells (positive for EGFP and EBFP) would lack scramblase activity. Contrary to this prediction, fused cells bound annexin $V$ (Supplementary Figure S4), indicating that T98G cells do not contain a potent scramblase inhibitor.

Extensive cytoplasmic vesicles are formed during apoptosis. While examining TRAIL-treated T98G and HCT116 cells by confocal microscopy, we noticed that annexin $\mathrm{V}$ staining included both cell surface binding and punctate cytoplasmic signals in apoptotic cells (Supplementary Figure S5). Further analysis by transmission electron microscopy revealed extensive formation of cytoplasmic vesicles in apoptotic Jurkat, HCT116 and T98G cells (Figures 2a, c and e). Interestingly, the frequency of these vesicles in sections of apoptotic cells was comparable for all three lines (Figure 2f). Similar cytoplasmic vesicles were observed in Jurkat cells undergoing apoptosis in response to etoposide, an agent previously shown to induce apoptosis in these cells through the mitochondrial pathway, ${ }^{20}$ as well as etoposide-treated HL-60, HCT116 and T98G cells; TRAIL-treated D32 and camptothecin-treated Daudi cells (Supplementary Figures S6a, b and d and data not shown). ${ }^{21}$ Vesicle formation was not affected by EGTA (data not shown) but was inhibited by Q-VD-OPh (Supplementary Figures S6e and f), suggesting that this process is caspasedependent.

Apoptotic cytoplasmic vesicles arise from the plasma membrane. To assess whether these cytoplasmic vesicles originated from the plasma membrane, cells were biotinylated using cell-impermeable reagents, ${ }^{17}$ treated with TRAIL or diluent, fixed, permeabilized, reacted with rhodaminecoupled streptavidin, and analyzed by confocal microscopy. Cells treated with diluent displayed biotin labeling only at the cell surface (Figures 3a, c and e), whereas apoptotic TRAILtreated cells exhibited punctate intracellular staining as well (Figures $3 b$, d and f). Likewise, staining of thin sections with gold-conjugated streptavidin revealed label almost exclusively on the surface of diluent-treated cells (Figures $3 \mathrm{~g}$ and i) but also associated with cytoplasmic vesicles in apoptotic cells (Figures $3 \mathrm{~h}$ and j). Collectively, these results identify the 

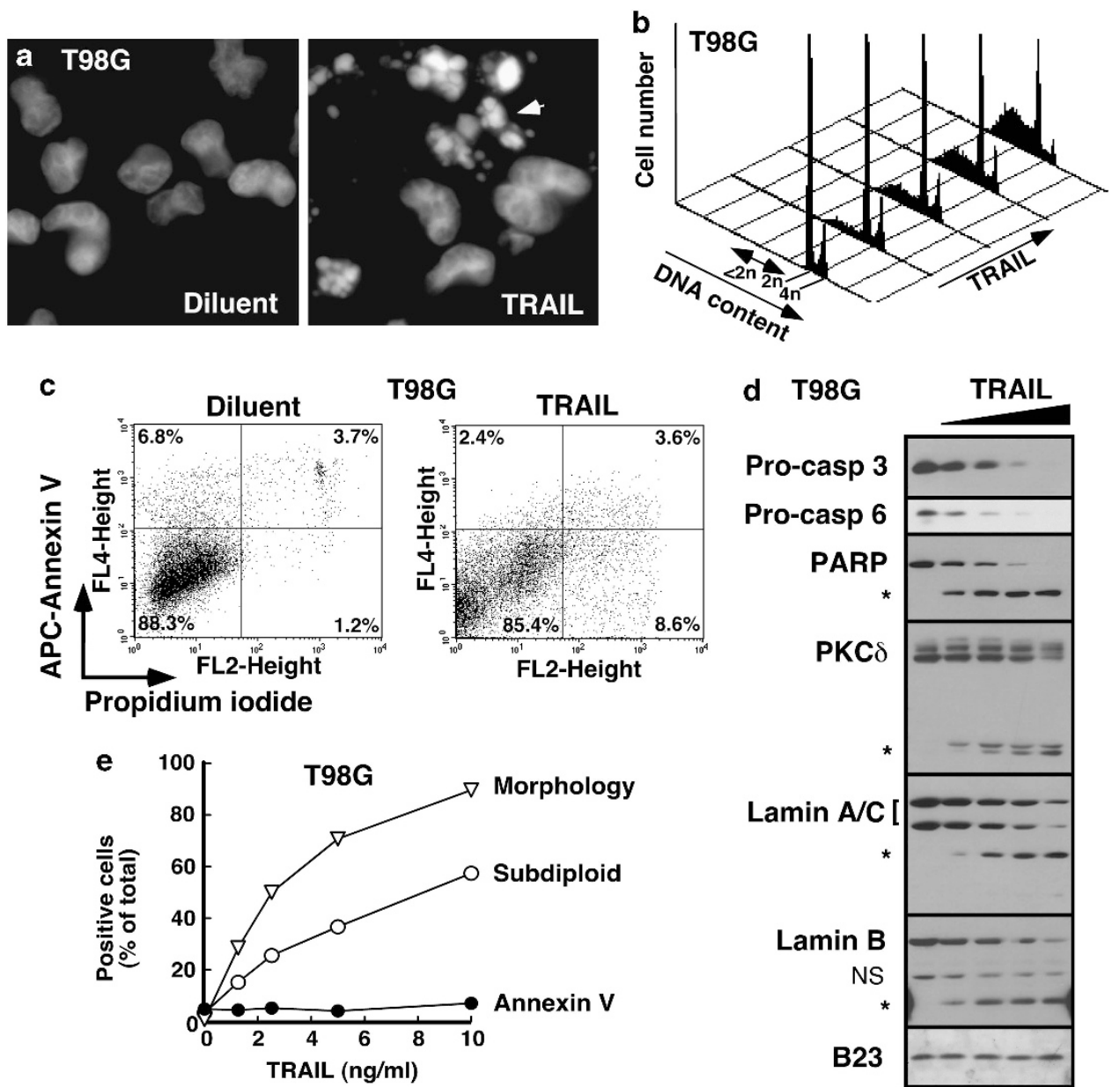

g
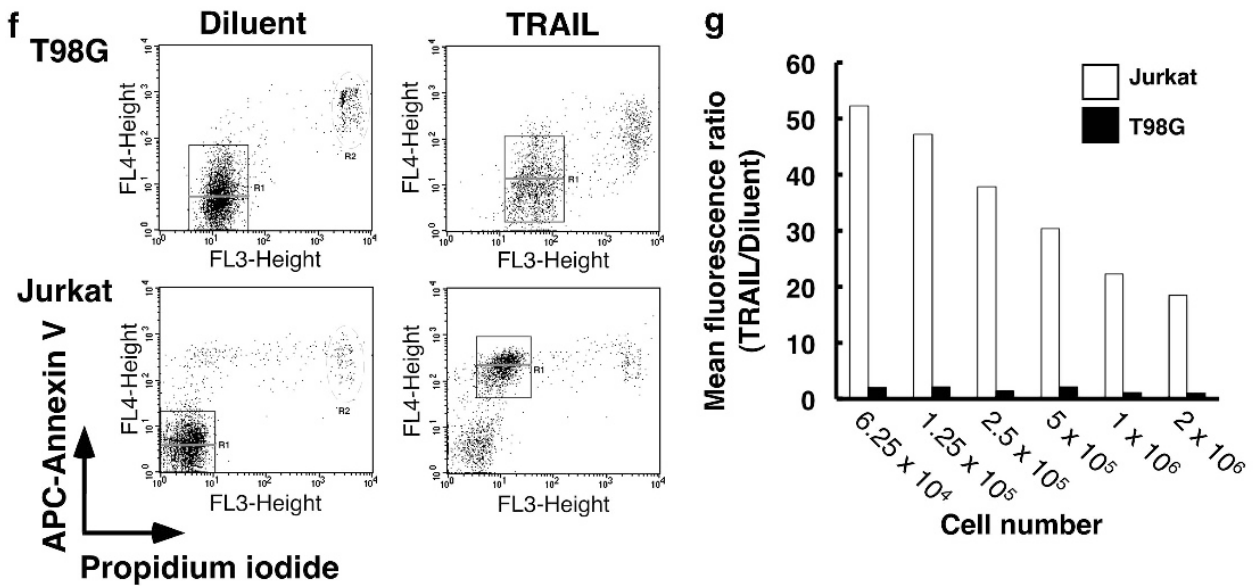

Cell number

Figure 1 TRAIL-induced apoptosis in T98G cells. (a-c) Cells were treated with $0,1.25,2.5,5$ or $10 \mathrm{ng} / \mathrm{ml}$ TRAIL for $4 \mathrm{~h}$, then split into separate aliquots containing $6 \times 10^{5}$ each and fixed in 3:1 methanol:acetic acid before staining with Hoechst and examination by fluorescence microscopy (a); incubated in flow cytometry buffer containing $0.1 \%$ Triton X-100, $50 \mu \mathrm{g} / \mathrm{ml} \mathrm{PI}$, and $0.1 \%$ sodium citrate overnight and examined by flow cytometry (b) or stained with annexin V-APC and $1 \mu \mathrm{g} / \mathrm{ml} \mathrm{PI}$ and analyzed by flow cytometry (c). The bulk of the untreated cells were assumed to be negative for annexin $\mathrm{V}$ staining; and only cells that stained brighter than this population (above the horizontal line) were considered positive. ${ }^{18}$ Numbers in each quadrant indicate $\%$ of total events. (d) In a separate experiment, whole cell lysates from T98G cells treated with $0,1.25,2.5$, 5 or $10 \mathrm{ng} / \mathrm{ml}$ TRAIL for $4 \mathrm{~h}$ were subjected to immunoblotting. *, caspase-induced fragments of the indicated antigens. NS denotes a nonspecific band. B23, which is not cleaved by caspases during apoptosis, ${ }^{43}$ served as a loading control. (e) Summary of results shown in panels (a-c). (f) T98G and Jurkat cells were either left untreated or treated with 25 or $10 \mathrm{ng} / \mathrm{ml} \mathrm{TRAIL}$, respectively, for $4 \mathrm{~h}$, after which cells were stained with annexin V-APC and $1 \mu \mathrm{g} / \mathrm{ml} \mathrm{PI}$, then analyzed by flow cytometry. Flow cytometer photomultiplier currents were set so that untreated Jurkat cells had a low annexin V-APC signal (region R1, lower left panel) and kept constant throughout the experiment so that binding to the two cell lines could be directly compared. Horizontal bars in R1 indicate mean fluorescence intensity. Circled area (R2) indicates annexin V binding in cells that have spontaneously become permeable. (g) Mean fluorescence intensities from samples in (f) and additional samples of untreated and treated T98G and Jurkat cells analyzed at the indicated cell concentrations were calculated using CellQuest software. Mean fluorescence ratios were calculated by dividing mean fluorescence intensities of treated and untreated cells. All results are representative of a minimum of three independent experiments 


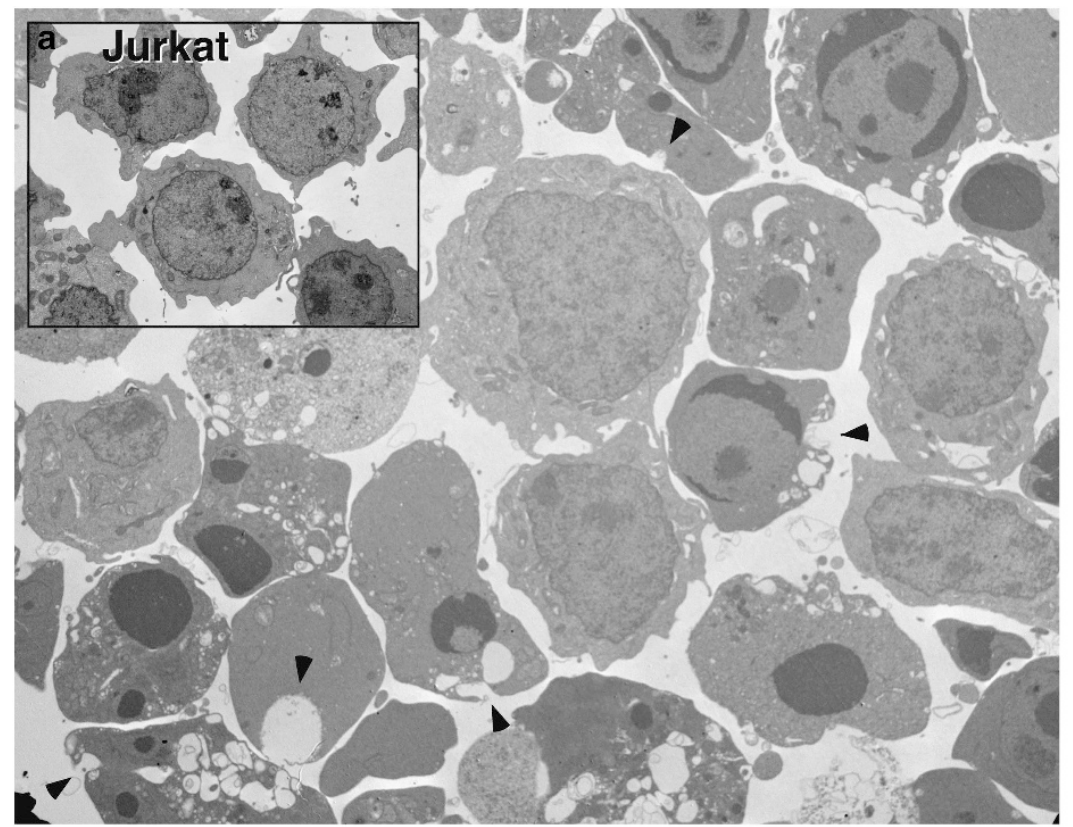

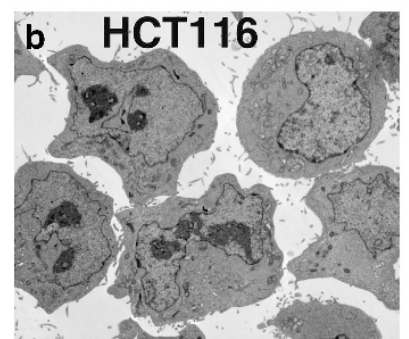

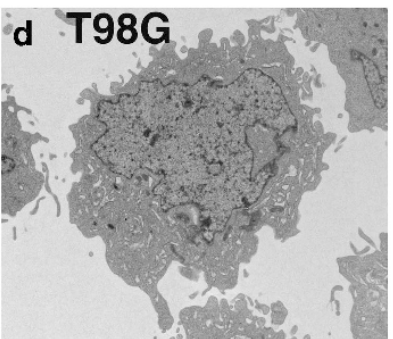

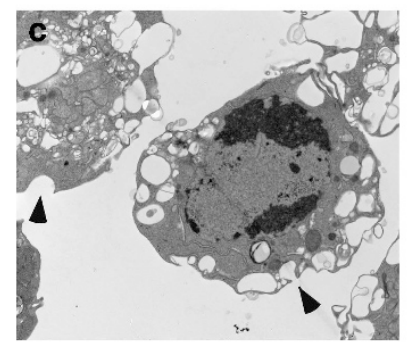

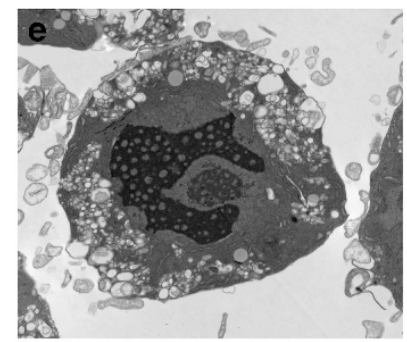

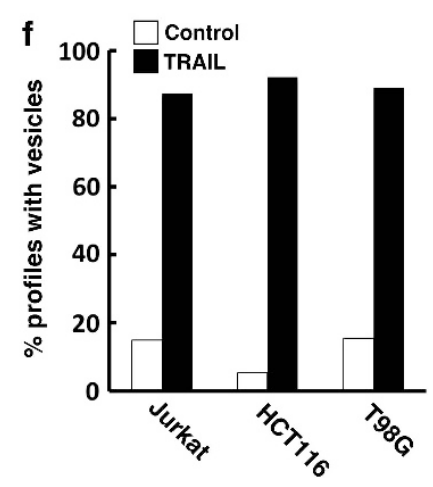

Figure 2 Formation of vesicles in cells undergoing apoptosis. (a-e) Jurkat (a), HCT116 (b and $\mathbf{c}$ ) and T98G cells ( $\mathbf{d}$ and $\mathbf{e}$ ) were either left untreated (a inset, $\mathbf{b}$ and $\mathbf{d}$ ) or treated with $5 \mathrm{ng} / \mathrm{ml}$ TRAIL (a, $\mathbf{c}$ and e) for $4 \mathrm{~h}$. At the completion of the TRAIL incubation, nonadherent cells were collected. All samples were analyzed by electron microscopy. (f) Percentage of untreated and nonadherent (apoptotic) TRAIL-treated cells with prominent cytoplasmic vesicles from experiments depicted in (a-e). A minimum of 90 profiles from two to three independent experiments were analyzed for each sample

plasma membrane as a source of the increased cytoplasmic vesicles in apoptotic cells.

Additional experiments were performed to rule out alternative sources of these vesicles. After transfection with LC-3B fused to EGFP, cells were treated with TRAIL or, as a positive control, rapamycin. LC-3B foci, a hallmark of autophagy, were increased in HCT116 cells but unchanged in Jurkat or T98G cells during TRAIL treatment (Figure 4a). Moreover, the autophagy inhibitors 3-methyladenine (3-MA) and chloroquine did not inhibit TRAIL-induced plasma membrane internalization (Figure 4b). Thus, the formation of cytoplasmic vesicles in apoptotic Jurkat and T98G cells cannot be attributed to autophagy.
In light of a recent study implicating lysosomes in PS externalization, ${ }^{15}$ we also assessed the potential role of lysosomes in apoptotic cytoplasmic vesicle formation. Staining with lysotracker green, a weak amine that accumulates in lysosomes because of their acidic $\mathrm{pH}$, was similar in control and TRAIL-treated cells (Figure 4c), suggesting that the lysosomal volume was similar. Moreover, when control and TRAIL-treated HCT116 and T98G were stained with lysotracker green and examined by confocal microscopy, there was no discernible change in the number or size of lysosomes (XWM and A Patel, unpublished observations). In addition, the lysosomal ATPase inhibitor bafilomycin A1, like chloroquine, failed to inhibit formation of the plasma 

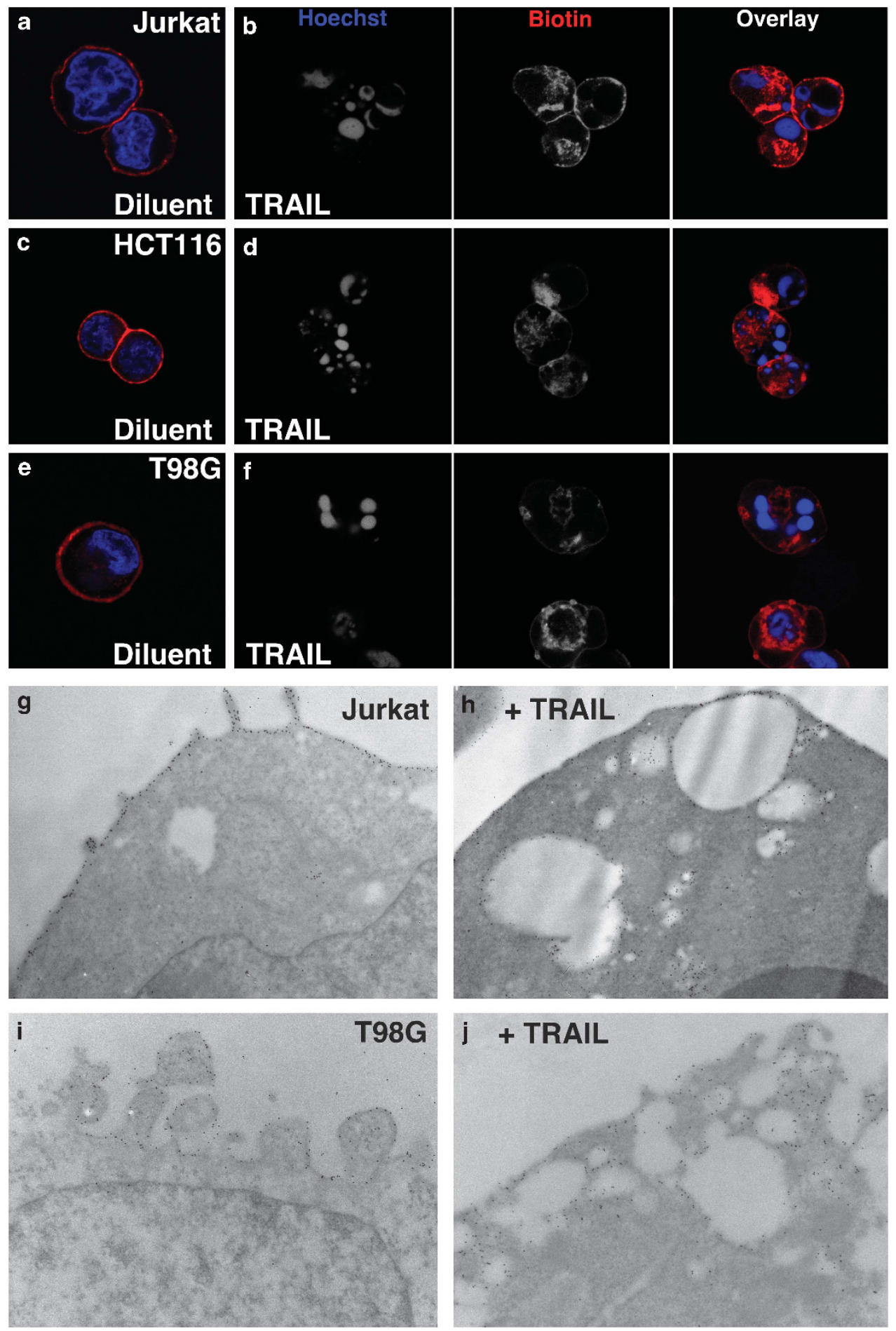

Figure 3 Vesicles formed during apoptosis appear to originate from the plasma membrane. (a-f) Jurkat (a and b), HCT116 (c and d) and T98G cells (e and f) were biotinylated, treated with diluent (a, c and e) or $25 \mathrm{ng} / \mathrm{ml}$ TRAIL (b, d and f) for $4 \mathrm{~h}$, fixed, permeabilized, stained with rhodamine-conjugated streptavidin and Hoechst 33258 and examined by confocal microscopy. ( $\mathbf{g}-\mathbf{j})$ Cells were biotinylated with cell impermeable reagents, washed, treated with diluent ( $\mathbf{g}$ and $\mathbf{i})$ or TRAlL ( $\mathrm{h}$ and $\mathbf{j}$ ) for $4 \mathrm{~h}$, washed, embedded in resin, stained with gold-conjugated anti-biotin antibody and visualized by electron microscopy

membrane-derived cytoplasmic vesicles (Figure 4b). Collectively, these observations argue against the possibility that the cytoplasmic vesicles observed in Figures 2 and 3 are lysosomes.
Further experiments examined whether various pathways previously implicated in plasma membrane internalization participate in formation of apoptosis-associated cytoplasmic vesicles. Transfection with the $\mathrm{C}$-terminal domain of the 
a
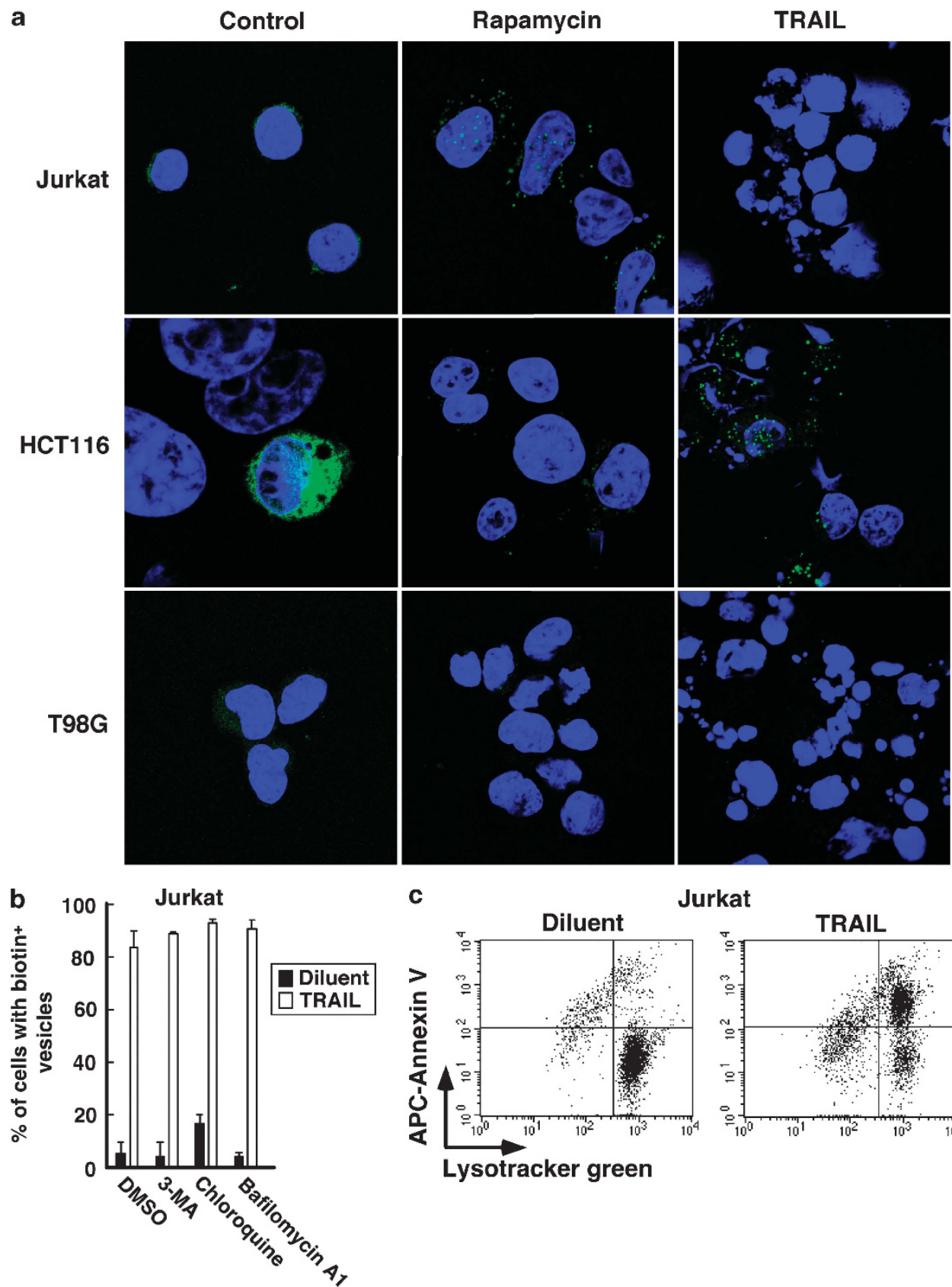

Jurkat

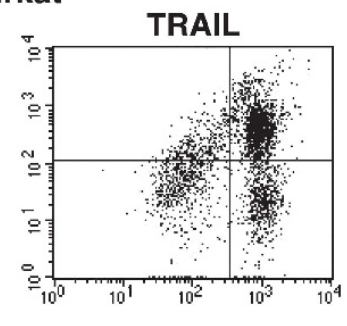

Lysotracker green

Figure 4 Effects of inhibitors on TRAIL-induced cytoplasmic vesicle formation. (a) Jurkat, HCT116 and T98G cells were transfected with EGFP-tagged LC-3B, incubated for $24 \mathrm{~h}$, treated with $10 \mathrm{nM}$ rapamycin for $24 \mathrm{~h}$ or $10 \mathrm{ng} / \mathrm{ml}$ TRAIL for $4-6 \mathrm{~h}$, fixed, stained with Hoechst 33258 and examined by confocal microscopy. (b) Following biotinylation with cell impermeable reagents, Jurkat cells were treated with diluent, $100 \mathrm{nM}$ bafilomycin $\mathrm{A} 1,10 \mu \mathrm{M}$ chloroquine or $1 \mathrm{mM} 3-\mathrm{MA}$ for 30-60 min, after which $12.5 \mathrm{ng} / \mathrm{ml}$ TRAIL was added for $4.5 \mathrm{~h}$ in the continued presence of the indicated inhibitor. After fixation, permeabilized cells were stained with rhodamine-coupled streptavidin and photographed as illustrated in Figure $3 \mathrm{~b}$. The presence versus absence of cytoplasmic streptavidin-avid vesicles was scored in a minimum of 50 cells. Results shown are the percentage of cells with readily detectable streptavidin-positive cytoplasmic vesicles, which were scored in normal cells in the control specimens and in apoptotic cells in the TRAlL-treated samples. Error bars, range of two independent experiments. (c) Jurkat cells were treated with diluent or $10 \mathrm{ng} / \mathrm{ml}$ TRAIL for $4.5 \mathrm{~h}$, stained with annexin V-APC and $1 \mu \mathrm{g} / \mathrm{ml}$ lysotracker green, and analyzed by flow cytometry

adapter protein AP-180, which inhibits clathrin-mediated endocytosis, $^{22}$ including endocytosis of CD71 in Jurkat cells, ${ }^{17}$ had no effect on apoptotic cytoplasmic vesicle formation (Figures $5 \mathrm{a}$ and b). Dominant negative Cdc42, dominant negative Arf6 and mutant dynamin 2, which inhibit various pathways of clathrin-independent endocytosis, likewise had no effect (Figure 5b), suggesting that processes leading to apoptotic plasma membrane internalization are clathrin- and dynamin-independent. Results with cytochalasin D (Figure 5c) likewise argue against involvement of the actin cytoskeleton.

Based on the observation that annexin $\mathrm{V}$ binding was only observed in cells with decreased volume ${ }^{2}$ and the realization that any decrease in cell volume has to be accompanied by a 
a
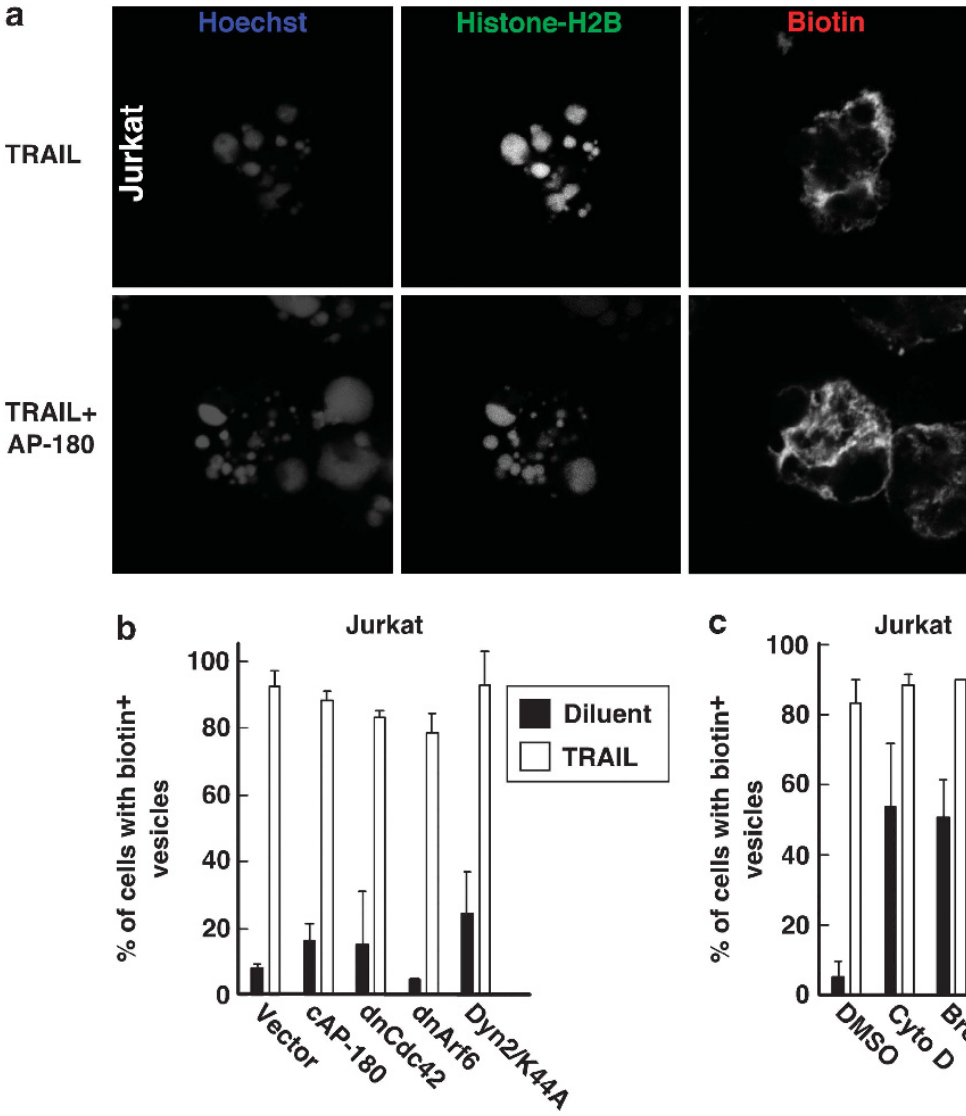
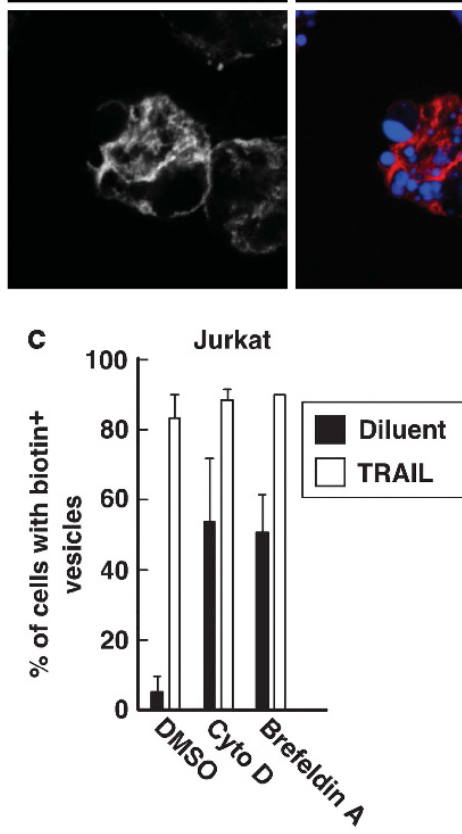

Figure 5 Dynamin-dependent endocytosis and actin polymerization do not play a role in cytoplasmic vesicle formation. (a) Jurkat cells were transfected with cAP-180 and EGFP-Histone H2B. After $24 \mathrm{~h}$, cells were biotinylated with cell impermeable reagents, then treated with diluent or $25 \mathrm{ng} / \mathrm{ml}$ TRAlL for $4 \mathrm{~h}$, fixed, permeabilized, stained with rhodamine-conjugated streptavidin, and examined by confocal microscopy. (b) Summary of results observed when Jurkat cells were transfected with the indicated construct, incubated for $24 \mathrm{~h}$, biotinylated using cell-impermeable reagents, exposed to diluent or $12.5 \mathrm{ng} / \mathrm{ml}$ TRAlL for $4.5 \mathrm{~h}$, fixed, permeabilized, stained with rhodamine-coupled streptavidin and examined by confocal microscopy. Results shown are the percentage of cells with readily detectable streptavidin-positive cytoplasmic vesicles, which were scored in normal cells in the diluent-treated specimens and in apoptotic cells in the TRAlL-treated samples. (c) After biotinylation of cell surface proteins, Jurkat cells were treated with diluent, $10 \mu \mathrm{M}$ cytochalasin D, or $5 \mu \mathrm{M}$ brefeldin A for 30-60 min, treated with diluent or $12.5 \mathrm{ng} / \mathrm{ml}$ TRAIL for $4 \mathrm{~h}$ in the continued presence of cytochalasin D or brefeldin A, processed and scored as described in the legend to Figure $4 \mathrm{~b}$. Error bars, range of two independent experiments (b and $\mathbf{c}$ )

decrease in surface area, resulting in excess plasma membrane, we postulated that cytoplasmic vesicle formation might result from cell shrinkage, another widely observed feature of apoptosis. ${ }^{23,24}$ To assess this possibility, we induced cell shrinkage by acute exposure to mannitol. ${ }^{25}$ Extensive intracellular vesicle formation similar to that seen in apoptotic cells was observed in mannitol-treated cells (Figures $6 a-d$ and $f$ ), raising the possibility that cytoplasmic vesicle formation reflects internalization of plasma membrane through mechanical processes when cells shrink during apoptosis or in response to osmotic stimuli. In contrast to etoposide-induced vesicle formation (Supplementary Figures S6e and f), mannitol-induced vesicle formation was not inhibited by Q-VD-OPh, suggesting that the mannitol-induced process is caspase-independent (Figures $6 \mathrm{e}$ and $\mathrm{f}$ ).

\section{Trafficking of plasma membrane-derived vesicles back} to the cell surface is diminished in cells with low apoptotic PS exposure. In complementary experiments, treatments that target lysosomes, impede autophagy, or inhibit dynamin-dependent endocytosis had no impact on
TRAIL-induced PS externalization (Supplementary Figure S7). Because previous studies suggested that $\mathrm{Ca}^{2+}$-mediated protein kinase $\mathrm{C} \delta$ activation contributes to PS externalization, ${ }^{26}$ we also examined the effects of the PKC $\delta$ inhibitor rottlerin and the $\mathrm{Ca}^{2+}$ chelator EGTA. While rottlerin failed to inhibit TRAIL-induced PS externalization in Jurkat and HCT116 cells, EGTA diminished PS externalization in both cell lines (Figure 7a; Supplementary Figure S7d) without affecting plasma membrane internalization (Figure $7 \mathrm{~b}$ ).

To further examine the role of $\mathrm{Ca}^{2+}$ in PS externalization, cells were treated with the $\mathrm{Ca}^{2+}$ ionophore ionomycin, which induces PS externalization in platelets and various somatic cells ${ }^{7,27}$ but has also been noted to induce a $\mathrm{Ca}^{2+}$-mediated membrane wound healing process. ${ }^{28,29}$ Like apoptotic stimuli, ionomycin triggered extensive PS externalization in Jurkat, HL-60 and K562 (Figure 7c and data not shown) but had a much smaller effect in T98G (Figures 7c and d), Daudi (Supplementary Figure S2f) and D32 (data not shown).

Because the same cells exhibit diminished PS externalization in response to apoptotic stimuli (Figure 1; Supplementary Figures S1 and S2) and ionomycin (Figure 7c; Supplementary 

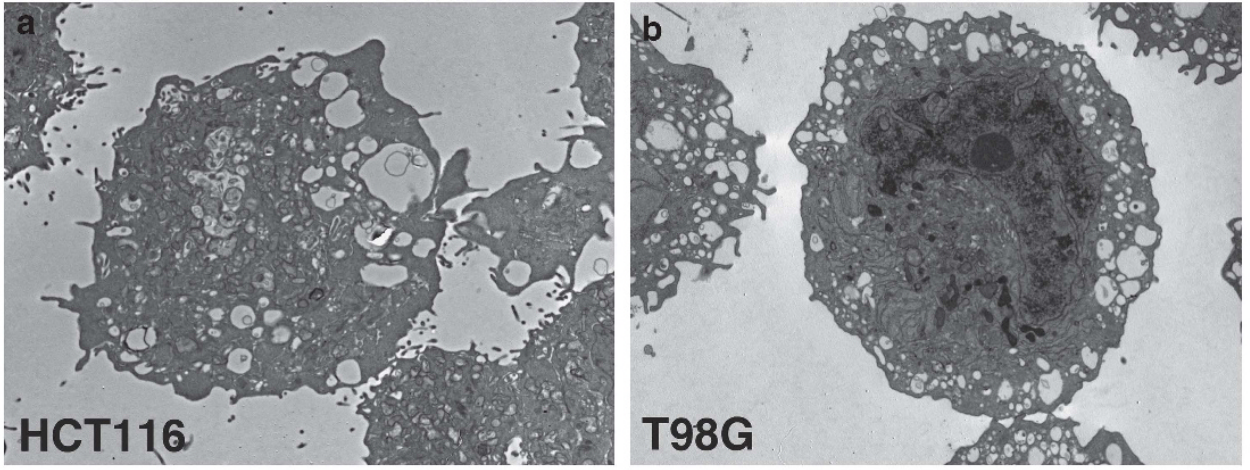

Diluent

Mannitol
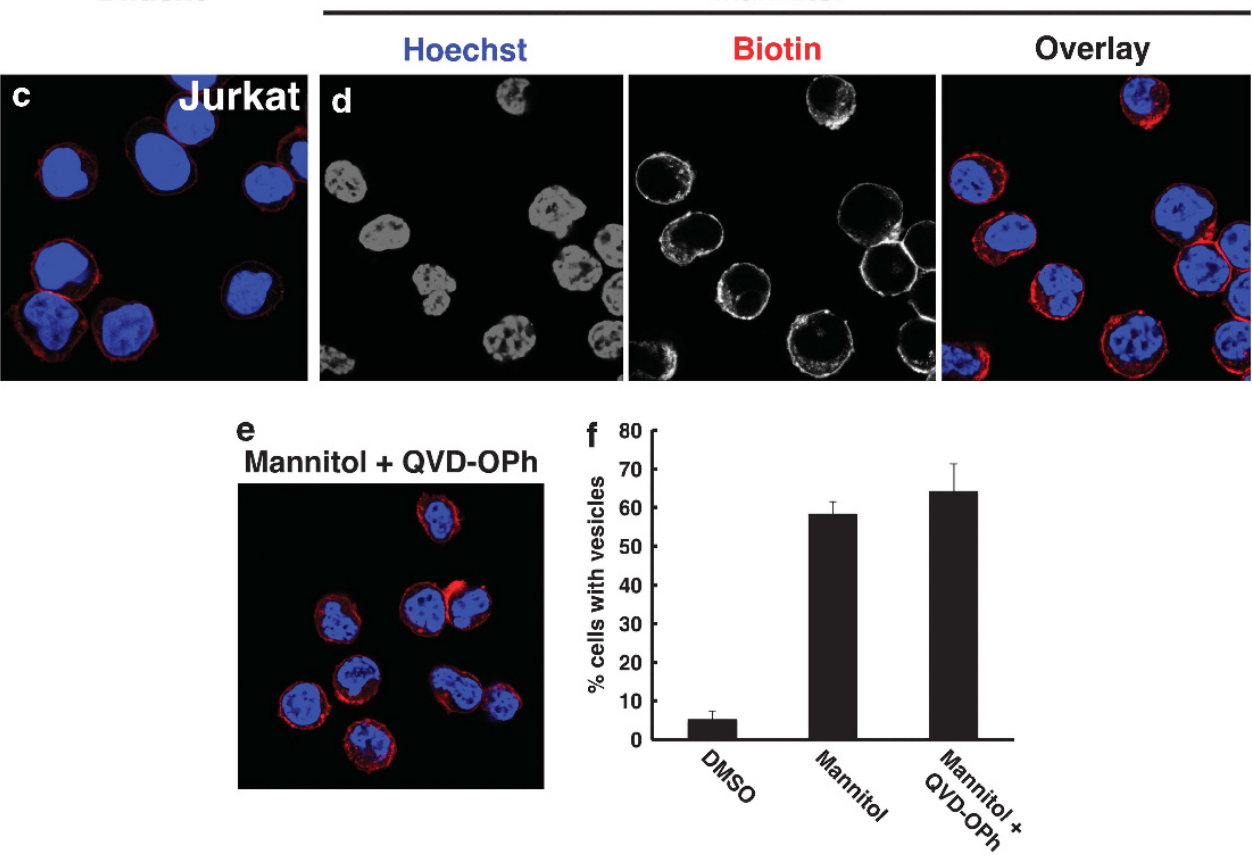

Figure 6 Mannitol induces vesicle formation. (a and b) HCT116 (a) and T98G (b) cells were treated with $500 \mathrm{mM}$ mannitol for 30 min and analyzed by electron microscopy. (c-e) Jurkat cells were biotinylated using cell impermeable reagents, pretreated with $5 \mu \mathrm{M}$ Q-VD-OPh for $30 \mathrm{~min}$ (e), treated with diluent (c) or $500 \mathrm{mM}$ mannitol (d, e) for $30 \mathrm{~min}$, fixed, permeabilized, stained with rhodamine-conjugated streptavidin and Hoechst 33258, and examined by confocal microscopy. (f) Percentage of cells with prominent cytoplasmic vesicles from experiments depicted in (c-e). A minimum of 50 profiles from two independent experiments were analyzed for each sample

Figure S2f), we examined whether diminished apoptotic PS externalization might reflect a defect in $\mathrm{Ca}^{2+}$-induced membrane trafficking. Electron microscopy revealed that the number of vesicles fusing with the plasma membrane after TRAIL treatment (arrowheads in Figures 2a and c) was highest in Jurkat cells, which externalize the most PS during apoptosis, and much lower in T98G cells, which bind much less annexin $\mathrm{V}$ (Figure 7e). These observations suggested a possible alteration in vesicle trafficking back to the cell surface in cells with diminished apoptotic PS exposure.

To further test this possibility, we followed the fate of plasma membrane by examining levels of endogenous cell surface CD71 (transferrin receptor) during apoptosis as outlined in Figure 8a. In both untreated and TRAIL-treated Jurkat cells, trypsin exposure led to decreased cell surface CD71 as expected $(9.5 \pm 3.0 \%$ and $26.7 \pm 10.1 \%$ of control signal remaining, respectively, Figure $8 b$, panels 1 and 2 ; Figure $8 \mathrm{c}$ ). During subsequent incubation at $37^{\circ} \mathrm{C}$ for $3 \mathrm{~h}$ (in the continued presence of TRAIL for treated cells), CD71 levels at the cell surface rose to $31.8 \pm 6.7 \%$ of control in untreated cells and $96.4 \pm 44.0 \%$ of control in TRAIL-treated cells. This increase could be inhibited by cycloheximide ( $\mathrm{CHX})$ in untreated cells, but to a much lesser degree in TRAILtreated cells (Figure 8b, panel 4), suggesting that new protein synthesis is required for the reappearance of CD71 on healthy cells but not apoptotic cells. In other words, these results provide direct evidence that internalized plasma membrane containing CD71 is cycled back to the cell surface in TRAILtreated Jurkat cells.

When the same experiment was performed in T98G cells, a different picture emerged. Trypsin treatment again reduced the CD71 signal in untreated and TRAIL-treated T98G cells to $15.5 \pm 4.2 \%$ and $37.5 \pm 7.4 \%$ of untreated cells, respectively (Figure 8d). When T98G cells were subsequently incubated at $37^{\circ} \mathrm{C}$ for $3 \mathrm{~h}$, whether $\mathrm{CHX}$ was present or not, TRAIL-treated T98G cells showed a relatively small increase in CD71 signal, 

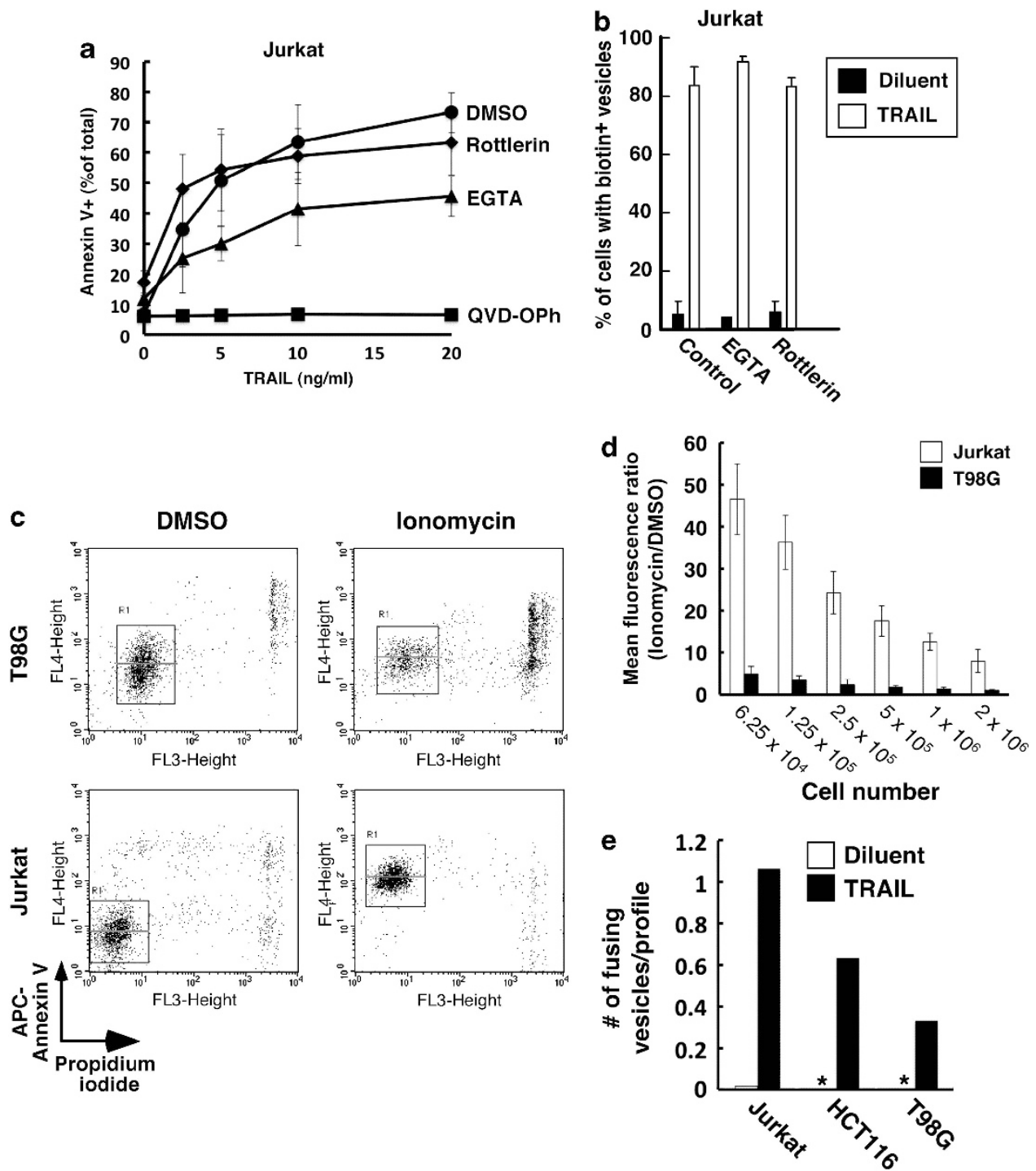

Figure 7 T98G exhibit a defect in $\mathrm{Ca}^{2+}$-induced PS externalization. (a) Jurkat cells were pretreated with diluent, $2 \mathrm{mM} \mathrm{EGTA,} 10 \mu \mathrm{M}$ rottlerin or $5 \mu \mathrm{M}$ Q-VD-OPh for $45 \mathrm{~min}$, treated with the indicated concentrations of TRAIL in the continued presence of the inhibitor, stained with annexin V-APC and analyzed by flow cytometry. (b) After biotinylation of cell surface proteins, Jurkat cells were treated with diluent, $2 \mathrm{mM} \mathrm{EGTA}$, or $10 \mu \mathrm{M}$ rottlerin for $45 \mathrm{~min}$, treated with diluent or $12.5 \mathrm{ng} / \mathrm{ml}$ TRAIL for $4 \mathrm{~h}$ in the continued presence of EGTA or rottlerin and processed as described in the legend to Figure $4 \mathrm{~b}$. Results shown are the percentage of cells with readily detectable streptavidinpositive cytoplasmic vesicles, which were scored in normal cells in the control specimens and in apoptotic cells in the TRAlL-treated samples. Error bars, range of two independent experiments. (c) T98G and Jurkat cells were treated with diluent or $2 \mu \mathrm{M}$ ionomycin for $15 \mathrm{~min}$, after which cells were stained with annexin V-APC and PI, then analyzed by flow cytometry. Flow cytometer photomultiplier currents were set so that untreated Jurkat cells had a low annexin V-APC signal (region R1, lower left panel) and kept constant throughout the experiment so that binding to the two cell lines could be directly compared. Horizontal bars in R1 indicate mean fluorescence intensity. (d) Mean fluorescence ratios calculated by dividing mean fluorescence intensities of treated and untreated cells from three independent experiments depicted in (c). Error bars in (a, d), \pm 1 S.D. of three independent experiments. (e) Cells were treated with $5 \mathrm{ng} / \mathrm{ml} \mathrm{TRAlL}$ for $4 \mathrm{~h}$, visualized by electron microscopy as illustrated in Figure 2 , and the number of vesicles fusing with the plasma membrane per cell was determined in a minimum of 90 cell profiles. ${ }^{*}$ indicates value of $<0.02$

suggesting that T98G cells have a defect in trafficking cytoplasmic vesicles back to the plasma membrane. This result, coupled with the diminished ability of these same cells to expose PS in response to ionomycin, suggests a defect in $\mathrm{Ca}^{2+}$-mediated membrane externalization that results in decreased PS exposure.

\section{Discussion}

Although annexin $V$ binding has been widely used to study apoptosis, the mechanistic basis for apoptotic PS exposure remains incompletely understood. Results of the present study suggest a two-step model (Figure 8e) in which internalization of plasma membrane to form cytoplasmic vesicles occurs as cells shrink during apoptosis and is followed by $\mathrm{Ca}^{2+}$-dependent trafficking of some of these vesicles back to the cell surface, leading to PS externalization.

In support of the first step, we observed accumulation of cytoplasmic vesicles in a variety of cells undergoing apoptosis in response to divers stimuli (Figures 2-5, Supplementary Figure S6). These vesicles were absent from nonapoptotic cells in the same samples (Figures 2a, b, $d$ and f). Importantly, 

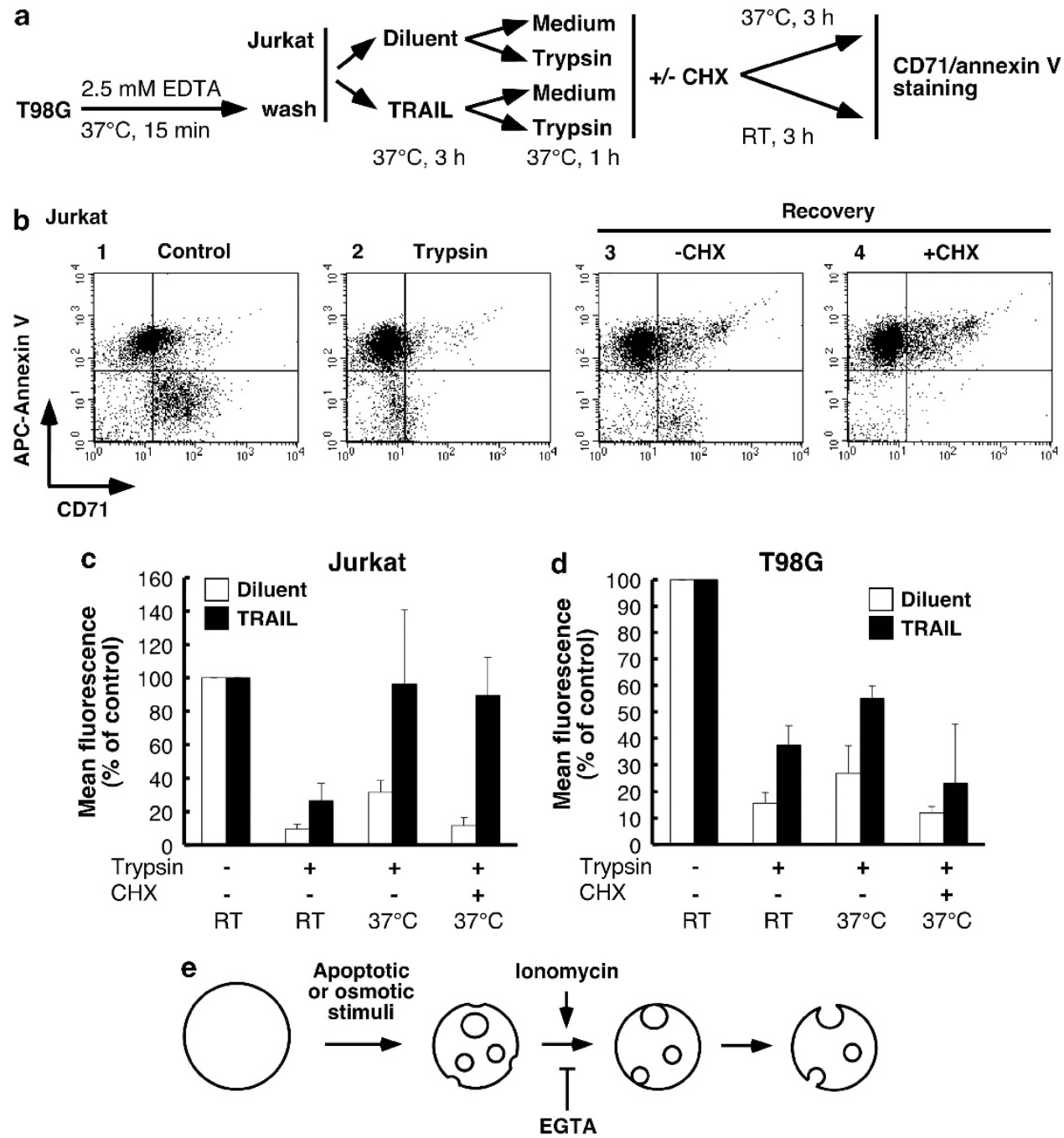

Figure 8 Plasma membrane protein CD71 is internalized during apoptosis and later reappears on the cell surface. (a) Experimental design. (b) Jurkat cells were treated with $10 \mathrm{ng} / \mathrm{ml}$ TRAIL for $3 \mathrm{~h}$ (panel 1) and incubated in trypsin for $1 \mathrm{~h}$. Cells were then washed and incubated for $3 \mathrm{~h}$ at RT (panel 2 ) or at $37^{\circ} \mathrm{C}$ in the absence (panel 3 ) or presence of $\mathrm{CHX}$ (panel 4). (c and d) Percent of mean fluorescence intensities of the indicated samples relative to control (diluent-treated, nontrypsinized) samples. Error bars, \pm S.D. of three independent experiments. (e) Model figure: Results described here indicate that plasma membrane is internalized as cells shrink during apoptosis, forming intracellular vesicles. This is followed by $\mathrm{Ca}^{2+}$-dependent trafficking of some of those cytoplasmic vesicles back to the plasma membrane, leading to PS externalization. The second step is defective in cells such as T98G, Daudi and D32, all of which form extensive cytoplasmic vesicles during apoptosis but externalize a very small percentage of the total cellular PS in response to either apoptotic stimuli or ionomycin

when cell surface proteins were derivatized using cellimpermeable biotinylating agents and then subjected to apoptotic stimuli, cytoplasmic vesicles within apoptotic cells were readily labeled with streptavidin (Figures $3,4 \mathrm{~b}$ and 5), suggesting the internalization of cell surface proteins. Streptavidin did not label similar structures in diluent-treated cells (Figure 3 ), indicating that their formation accompanies apoptosis.

Several observations also provide evidence that trafficking of these vesicles back to the cell surface contributes to PS externalization. First, more vesicles fusing with the plasma membrane are seen in cell lines that externalize more PS during apoptosis (Figures 2 and 7e). Second, the plasma membrane protein CD71 rapidly reappears on the surface of trypsin-shaved Jurkat cells undergoing apoptosis but not on the surface of trypsin-shaved nonapoptotic cells, suggesting an increased flux of membrane proteins to the cell surface during apoptosis (Figures $8 \mathrm{~b}$ and $\mathrm{c}$ ). Importantly, this flux in apoptotic cells was unaffected by $\mathrm{CHX}$ (Figures $8 \mathrm{~b}$ and $\mathrm{c}$ ), suggesting that the protein (and lipid) movement reflects plasma membrane trafficking that is independent of protein synthesis. Third, this $\mathrm{CHX}$-resistant trafficking of CD71 back to the cell surface was markedly diminished in T98G cells, which externalize much less PS than Jurkat cells (Figure 8d). Finally, cell lines with lower apoptotic PS exposure also exhibited lower ionomycin-induced membrane trafficking (Figures 7c and d; Supplementary Figure S4). Collectively, these results provide strong evidence for the second step depicted in Figure 8e.

While our study was in progress, Mirnikjoo et al. ${ }^{15}$ reported that PS exposure in apoptotic HeLa cells reflects $\mathrm{Ca}^{2+}$. dependent trafficking of lysosomes to the plasma membrane. 
Several observations in the present study are not consistent with this model. First, we did not observe any change in lysosomal mass, as assessed by lysotracker green staining, that would suggest increased lysosomal mass early during the apoptotic process or decreased lysosomal mass as cells become annexin V positive (Figure 4c). Second, we could not detect any inhibitory effect of agents that disrupt lysosomal function, including chloroquine and bafilomycin $A 1$, on apoptotic cytoplasmic vesicle formation or subsequent PS exposure (Figure 4b; Supplementary Figures S7a and d). While it is possible that a small number of lysosomes traffic to the cell surface along with the plasma membrane-derived cytoplasmic vesicles, our observations argue against the possibility that lysosomes are the major source of cell surface PS during apoptosis.

It is interesting to compare the PS externalization process proposed in Figure $8 \mathrm{e}$ with other processes that lead to annexin $\mathrm{V}$ binding. Nagata and colleagues have traced the $\mathrm{Ca}^{2+}$-triggered PS externalization that provides a lipid platform for assembling coagulation factors on activated platelets ${ }^{7}$ to the scramblase activity of TMEM16F. ${ }^{14}$ On the other hand, PS is also detectable on the surfaces of membraneenclosed nuclei that are released from maturing erythroblasts; ${ }^{30}$ and the release of these effete nuclei has been shown to involve a vesicle-mediated membrane fusion process. ${ }^{31}$ Moreover, $\mathrm{Ca}^{2+}$-stimulated PS exposure on murine B cells, which varies from strain to strain, has been shown to depend on cell shrinkage, ${ }^{32}$ consistent with the findings summarized in Figure $8 \mathrm{e}$. Whether cell shrinkage and/or membrane fusion, as opposed to scramblase activation, also plays a similar role in the currently unexplained appearance of PS on the surface of activated T lymphocytes ${ }^{33}$ and on tumor exosomes ${ }^{34}$ remains to be determined.

Consistent with earlier reports, ${ }^{8,16}$ we readily identified several cell lines in which apoptotic PS exposure was difficult to detect (Figure 1; Supplementary Figures S1 and S2) even when we decreased the cell number (Figures $1 \mathrm{f}$ and $\mathrm{g}$ ) as suggested $^{8}$ or increased the annexin $\mathrm{V}$ concentration in the assays to compensate for nonsaturating amounts of annexin $\mathrm{V}$ provided in commercial kits (S-HL, unpublished observations). In the present study, we showed for the first time that diminished PS externalization was also seen when the same cell lines were treated with ionomycin (Figures 7c and d; Supplementary Figure S2f), a classical stimulus of $\mathrm{Ca}^{2+}$ mediated membrane repair, and traced this effect to diminished fusion of vesicles with the cell surface (Figures 2 and 7e) rather than a lack of putative scramblases (Supplementary Figures $S 3 b-d$ ) or the presence of a scramblase inhibitor (Supplementary Figure S4).

Future studies will undoubtedly help refine the mechanism proposed in Figure 8e. Our model postulates that plasma membrane internalization is the first step; but the usual participants in endocytosis, including clathrin, dynamin and actin do not appear to play a role (Figure 5). Our model also postulates that the second step in PS externalization reflects $\mathrm{Ca}^{2+}$-mediated trafficking of many of these same vesicles to the cell surface. Although lysosomes have been most often found to be the organelle that traffics to the breach when the plasma membrane of nonapoptotic cells is mechanically disrupted, ${ }^{29,35}$ other membranous organelles have also been observed to traffic in this fashion. ${ }^{28}$ The protein components of this $\mathrm{Ca}^{2+}$-activated membrane trafficking machinery remain largely unidentified ${ }^{28,36}$ and might even vary from cell type to cell type. ${ }^{37}$ The present demonstration that T98G, Daudi and D32 cells all have a defect in this machinery might provide an opportunity to identify additional components of this pathway.

PS is normally found on the cytoplasmic leaflet of endocytic vesicles. We envision two potential processes that could lead to the accessibility of PS on the cell surface after vesicle fusion. First, upon internalization, the vesicles formed as cells shrink might not traffic to specific compartments as ordinary endocytic vesicles would. Lacking the optimal environment or machinery to maintain proper membrane asymmetry, ${ }^{38}$ vesicles may expose PS on the luminal leaflet, resulting in PS externalization upon fusion with the plasma membrane. Alternatively, vesicles that contain PS on their cytoplasmic surfaces may be trafficked to the plasma membrane by the machinery that participates in the wound healing process, patching areas of the plasma membrane and resulting in PS exposure. ${ }^{38}$ Further studies are needed to distinguish between these models.

In summary, the present results suggest that apoptotic PS externalization results from a two-step process (Figure $8 \mathrm{e}$ ) that begins with the internalization of plasma membrane as cells shrink during apoptosis, forming intracellular vesicles that are then trafficked back to the cell surface in a $\mathrm{Ca}^{2+}$-dependent manner. Importantly, this second step is markedly diminished in cell lines with diminished apoptotic PS exposure.

\section{Materials and Methods}

Materials. Recombinant human TRAIL (rhTRAIL) was purchased from R\&D Systems (Minneapolis, MN, USA); etoposide and ionomycin $\left(\mathrm{Ca}^{2+}\right.$ salt) from Enzo Life Sciences (Plymouth Meeting, PA, USA); allophycocyanin (APC)conjugated annexin $V$ and anti-human CD71 from BD Pharmingen (San Diego, $\mathrm{CA}, \mathrm{USA}$ ); D-biotin, rhodamine-conjugated streptavidin and fluorescein isothiocyanate (FITC)-conjugated annexin V from Invitrogen (Carlsbad, CA, USA); streptolysin $O$ from Sigma (St Louis, MO, USA); polyethylene glycol 1500 from Roche (Indianapolis, IN, USA); Q-VD-OPh from SM Biochemicals (Anaheim, CA, USA) and PCR master mix from Promega (Madison, WI, USA).

Cell culture. Jurkat and Daudi cells were cultured in medium A, which consisted of RPMI 1640 medium with $10 \%$ (v/v) heat-inactivated fetal bovine serum (FBS). T98G cells (American Type Culture Collection, Manassas, VA, USA) were maintained in medium A supplemented with $1 \mathrm{mM}$ sodium pyruvate. HCT116 cells from Bert Vogelstein (Johns Hopkins University, Baltimore, MD, USA) were cultured in McCoy's 5A medium with 10\% FBS. D32 cells provided by C David James (University of California, San Francisco, CA, USA) were grown in Dulbecco's modified essential medium with $1 \mathrm{mM}$ sodium pyruvate. All media contained 40 units $/ \mathrm{ml}$ penicillin $\mathrm{G}, 40 \mu \mathrm{g} / \mathrm{ml}$ streptomycin and $1 \mathrm{mM}$ glutamine unless indicated otherwise.

RT-PCR. Total RNA was isolated from cells using an RNeasy isolation kit (Qiagen, Valencia, CA, USA) according to the supplier's instructions and treated with RNase-free DNase I (Invitrogen) for $15 \mathrm{~min}$ at $21^{\circ} \mathrm{C}$. RT-PCR was performed using the SuperScript III First Strand kit (Invitrogen). PLSCR, ATPase family members, and TMEM16F were amplified using primers shown in Supplementary Table S1 and the following conditions: 2 min at $95^{\circ} \mathrm{C} ; 30-40$ cycles $\left(30 \mathrm{~s}\right.$ at $95^{\circ} \mathrm{C}$, $30 \mathrm{~s}$ at $55^{\circ} \mathrm{C}$, and $60 \mathrm{~s}$ at $72{ }^{\circ} \mathrm{C}$ ); final extension $5 \mathrm{~min}$ at $72^{\circ} \mathrm{C}$.

Transient transfections. Cells were transfected with $40 \mu \mathrm{g}$ plasmid encoding LC-3B fused to EGFP using a BTX 830 square wave electroporator (BTX, San Diego, CA, USA) programmed to deliver a $10-\mathrm{ms}$ pulse at $280 \mathrm{~V}$ for Jurkat cells, 320 V for HCT116 cells, and 240 V for T98G cells. 
Stable transfections. To generate stable cell lines, $1 \times 10^{7}$ T98G or Jurkat cells were transfected with $40 \mu \mathrm{g}$ plasmid encoding EBFP or EGFP, respectively, using a 10 -ms pulse at 240 or $280 \mathrm{~V}$. At $48 \mathrm{~h}$ after transfection, the cells were switched to medium containing $800 \mu \mathrm{g} / \mathrm{ml} \mathrm{G} 418$. Once G418-resistant T98G colonies formed, clones were isolated using cloning rings and assayed for transgene expression by flow cytometry. Similarly, once G418-resistant Jurkat cells grew up, clones were isolated by limiting dilution and assayed for transgene expression by flow cytometry.

Cell fusion. To determine whether inhibitors of PS externalization were present in T98G cells, cell fusion was performed. Equal numbers of Jurkat cells stably expressing EGFP and T98G cells stably expressing EBFP were combined and pelleted at $50 \times \mathrm{g}$. Cell fusion was initiated using polyethylene glycol 1500 following the supplier's instructions. Following fusion, cells were collected by centrifugation, resuspended in T98G culture medium, and seeded. After $24 \mathrm{~h}$, cells were treated with ionomycin, then stained with annexin $\mathrm{V}$ and $\mathrm{PI}$ as described below.

Apoptosis assays. After treatment with the indicated concentrations of TRAIL for $4-6 \mathrm{~h}$ or topoisomerase poisons for $24 \mathrm{~h}$, cells were fixed in $3: 1$ (v:v) methanol:acetic acid, dropped onto glass slides, air dried, stained with $1 \mu \mathrm{g} / \mathrm{ml}$ Hoechst 33258 , and visualized by fluorescence microscopy. To assess DNA fragmentation, cells were incubated in buffer containing $0.1 \%(\mathrm{w} / \mathrm{v})$ Triton X-100, $50 \mu \mathrm{g} / \mathrm{ml} \mathrm{Pl}$ and $0.1 \%$ (w/v) sodium citrate overnight at $4{ }^{\circ} \mathrm{C}$ and analyzed by flow cytometry. ${ }^{39}$

Treatment with streptolysin 0 or ionomycin. Cells were washed once with serum-free RPMI 1640 medium, incubated in medium containing $0.8 \mathrm{U} / \mathrm{ml}$ streptolysin $\mathrm{O}$ for $10 \mathrm{~min}$ at $37^{\circ} \mathrm{C}$ to facilitate annexin $\mathrm{V}$ penetration ${ }^{40}$ or in medium containing the indicated concentration of ionomycin for $15 \mathrm{~min}$ at $37^{\circ} \mathrm{C}$ to trigger PS exposure. ${ }^{41}$ Cells were then washed once with serum-free medium prior to annexin $\mathrm{V}$ staining.

Annexin V binding by flow cytometry. Binding of APC-conjugated annexin $\mathrm{V}$ to cells was assessed as originally described. ${ }^{2,3}$ The indicated number of cells were stained with annexin $\mathrm{V}$ (at the concentration suggested by the supplier) and $0.1 \mu \mathrm{g} / \mathrm{ml} \mathrm{Pl}$ for $15 \mathrm{~min}$ in $100 \mu \mathrm{l}$ annexin $\mathrm{V}$ buffer consisting of $140 \mathrm{mM} \mathrm{NaCl}, 2.5 \mathrm{mM} \mathrm{CaCl}_{2}$ and $10 \mathrm{mM} \mathrm{HEPES}(\mathrm{pH}$ 7.4). At the conclusion of the incubation, samples were diluted with $400 \mu \mathrm{l}$ annexin V buffer and immediately subjected to flow cytometry. In all, 20000 events were collected from the FL3 (excitation $488 \mathrm{~nm}$, emission $650 \mathrm{LP}$ ) and FL4 (excitation $635 \mathrm{~nm}$, emission $661 \pm 8 \mathrm{~nm}$ ) channels of a Becton Dickinson FACSCalibur or FACSCanto flow cytometer (Becton Dickinson, Franklin Lakes, NJ, USA). Data analysis was performed using Becton Dickinson CellQuest software (BD Biosciences, Franklin Lakes, NJ, USA).

Electron microscopy. Log phase cells (40-50\% confluent) were treated with the indicated concentrations of TRAIL in their respective growth media for $4 \mathrm{~h}$ or etoposide for $6 \mathrm{~h}$. At the completion of the incubation, HCT116 and T98G cells were separated into nonadherent (collected on ice) and adherent fractions (released by $10 \mathrm{~min}$ treatment with trypsin-EDTA). The fractions or the total Jurkat cell population were sedimented at $50 \times g$, washed once with ice-cold phosphatebuffered saline (PBS), and fixed at least overnight in Trump's fixative at $4{ }^{\circ} \mathrm{C}$. Samples were then washed with phosphate buffer, dehydrated through a series of ethanol washes, embedded in Embed 812/Araldite resin, post-fixed in 1\% osmium tetroxide, and stained with uranyl acetate and lead citrate by standard techniques. In all, 10-20 randomly chosen fields were photographed at $\times 2500-3000$ magnification on a Jeol 1400 (Jeol, Inc., Peabody, MA, USA) transmission electron microscope and examined for the appearance of cytosolic vesicles.

Biotinylation of cell surface proteins. T98G and HCT116 cells were released by brief treatment in EGTA and diluted with their respective media. These cells or Jurkat cells were sedimented at $100 \times g$ for $6 \mathrm{~min}$, and washed three times with ice-cold PBS containing $0.1 \mathrm{mM} \mathrm{CaCl} 2$ and $1 \mathrm{mM} \mathrm{MgCl} 2$ (PBS-CM). Cell surface proteins were biotinylated by incubating cells in $1.0 \mathrm{ml} \mathrm{PBS-CM}$ containing $1 \mathrm{mM}$ NHS-LC-Biotin (Pierce, Rockford, IL, USA) on ice for $1 \mathrm{~h}$. The reaction was stopped by incubating cells with ice-cold PBS-CM containing $100 \mathrm{mM}$ glycine. After three washes with PBS-CM, cells were resuspended in their respective media and incubated with diluent or rhTRAIL at $37^{\circ} \mathrm{C}$ for $4 \mathrm{~h}$. Samples were then sedimented at $100 \times g$ for 5 min, washed once with ice-cold PBS, fixed in $4 \% \mathrm{EM}$ grade glutaraldehyde in PBS for 15 min, washed, dehydrated and embedded in LR White resin.

To detect biotinylated proteins, $100 \mathrm{~nm}$ thick sections were collected on Ni grids; hydrated in $0.1 \mathrm{M}$ phosphate buffer followed by Target Retrieval Solution (DAKO, Carpentaria, CA, USA) for $20 \mathrm{~min}$ at $21^{\circ} \mathrm{C}$, blocked in PBS containing $10 \%(\mathrm{v} / \mathrm{v})$ normal goat serum and $0.05 \%(\mathrm{w} / \mathrm{v})$ Tween 20 for $60 \mathrm{~min}$ at $21^{\circ} \mathrm{C}$, incubated with goat anti-biotin antibody coupled to $10 \mathrm{~nm}$ gold particles (BBI Research, Madison, WI, USA) overnight at $4^{\circ} \mathrm{C}$, rinsed six times with $0.1 \mathrm{M}$ phosphate buffer and three times with water, and examined using a Philips Tecnai 12 transmission electron microscope (FEI, Hillsboro, OR, USA).

Confocal microscopy. Where indicated, T98G and HCT116 cells growing on coverslips were biotinylated by incubation in cell culture medium containing $1 \mathrm{mM}$ NHS-LS-Biotin at $37^{\circ} \mathrm{C}$ for $1 \mathrm{~h}$. After three washes with fresh medium, cells were treated with diluent or TRAIL at $37^{\circ} \mathrm{C}$ for $4 \mathrm{~h}$. Cells were then stained with FITC-annexin $V$ in annexin $V$ buffer on ice for $40 \mathrm{~min}$, washed three times with calcium- and magnesium-free Dulbecco's PBS, fixed in 4\% (v/v) paraformaldehyde in PBS for $10 \mathrm{~min}$ at $21^{\circ} \mathrm{C}$ and examined as described below. Alternatively, treated cells were washed with PBS and stained with rhodamine-conjugated streptavidin in PBS containing $0.1 \%(\mathrm{w} / \mathrm{v})$ saponin and $2 \%$ FCS for $30 \mathrm{~min}$ at $21^{\circ} \mathrm{C}$. Samples were then washed three times with PBS and counterstained with $1 \mu \mathrm{g} / \mathrm{ml}$ Hoechst 33258 in PBS. Images were captured on a Zeiss LSM 710 (Carl Zeiss Microscopy, L.L.C., Thorwood, NY, USA) scanning confocal microscope with a $\times 100 / 1.4$ N.A. oil immersion objective. Quantitation and image processing were performed with the Zeiss Zen software (Carl Zeiss Microscopy, L.L.C.) package and Adobe Photoshop CS3.

Immunoblotting. Western blotting was performed as previously described. ${ }^{42}$ Membranes were probed with the following antibodies: murine monoclonal antiprocaspase 3 from BD Biosciences, rabbit polyclonal anti-procaspase 6 from Cell Signaling Technology (Beverly, MA, USA), murine monoclonal anti-PLSCR1 or rabbit polyclonal anti-PKC $\delta$ from Santa Cruz Biotechnology (Santa Cruz, CA, USA), chicken polyclonal anti-lamin $B,{ }^{43}$ murine monoclonal anti-PARP (Guy Poirier, Laval University, Ste-Foy, Quebec, Canada), murine monoclonal anti-lamin A/C (Frank McKean, Harvard University) or, as a loading control, chicken anti-B23/nucleophosmin. ${ }^{43}$

CD71 staining. T98G cells were detached from flasks using $2.5 \mathrm{mM}$ EDTA in PBS prior to treatment. Jurkat and T98G cells were either left untreated or treated with 10 or $25 \mathrm{ng} / \mathrm{ml}$ TRAIL, respectively, for $3 \mathrm{~h}$. Cells were then incubated in medium $\mathrm{A}$ or trypsin for $1 \mathrm{~h}$ at $37^{\circ} \mathrm{C}$ to remove cell surface $\mathrm{CD} 71$. Medium with or without TRAIL and/or $30 \mu \mathrm{g} / \mathrm{ml} \mathrm{CHX}$ was added as indicated; and cells were incubated for $3 \mathrm{~h}$ at $21^{\circ} \mathrm{C}$ or at $37^{\circ} \mathrm{C}$. At the completion of treatment, cells were stained with murine anti-human CD71 (BD Pharmingen) in $100 \mu \mathrm{l}$ buffer consisting of $2 \%(\mathrm{w} / \mathrm{v})$ bovine serum albumin in PBS, washed twice with PBS, stained with FITC-labeled goat anti-mouse IgG (Southern Biotech) and APC-conjugated annexin $\mathrm{V}$ and immediately analyzed by flow cytometry. In all, 20000 events were collected from the FL1 (excitation $488 \mathrm{~nm}$, emission 530/30) and FL4 (excitation $633 \mathrm{~nm}$, emission 660/20) channels of a Becton Dickinson FACSCanto II flow cytometer. Data were analyzed using CellQuest software (BD Biosciences).

\section{Conflict of Interest}

The authors declare no conflict of interest.

Acknowledgements. This work was supported in part by R01 CA69008 and a predoctoral fellowship to S-HL from the Mayo Foundation for Education and Research. We gratefully acknowledge use of the Mayo Clinic Flow Cytometry and Electron Microscopy Core Facilities; assistance of Trace Christensen, Scott Gamb and Cindy Uhl with the electron micrographs; assistance of Anand Patel and Kevin Peterson with confocal microscopy and cell size determinations, respectively; and helpful conversations with Greg Gores.

1. Fadok VA, Voelker DR, Campbell PA, Cohen JJ, Bratton DL, Henson PM. Exposure of phosphatidylserine on the surface of apoptotic lymphocytes triggers specific recognition and removal by macrophages. J Immunol 1992; 148: 2207-2216.

2. Koopman G, Reutelingsperger CP, Kuijten GA, Keehnen RM, Pals ST, van Oers MH. Annexin $\mathrm{V}$ for flow cytometric detection of phosphatidylserine expression on $\mathrm{B}$ cells undergoing apoptosis. Blood 1994; 84: 1415-1420. 
3. Martin SJ, Reutelingsperger CP, McGahon AJ, Rader JA, van Schie RC, LaFace DM et al. Early redistribution of plasma membrane phosphatidylserine is a general feature of apoptosis regardless of the initiating stimulus: inhibition by overexpression of $\mathrm{Bcl}-2$ and $\mathrm{Abl}$. J Exp Med 1995; 182: 1545-1556.

4. Zullig S, Neukomm LJ, Jovanovic M, Charette SJ, Lyssenko NN, Halleck MS et al. Aminophospholipid translocase TAT-1 promotes phosphatidylserine exposure during C. elegans apoptosis. Curr Biol 2007; 17: 994-999.

5. Schlegel RA, Williamson P. P.S. to PS (phosphatidylserine)-pertinent proteins in apoptotic cell clearance. Sci STKE 2007; 2007: pe57.

6. Zhou Z. New phosphatidylserine receptors: clearance of apoptotic cells and more. Developmental Cell 2007; 13: 759-760.

7. Zwaal RF, Comfurius P, Bevers EM. Surface exposure of phosphatidylserine in pathological cells. Cell Mol Life Sci 2005; 62: 971-988.

8. van Genderen $\mathrm{H}$, Kenis $\mathrm{H}$, Lux $\mathrm{P}$, Ungeth $\mathrm{L}$, Maassen $\mathrm{C}$, Deckers $\mathrm{N}$ et al. In vitro measurement of cell death with the annexin A5 affinity assay. Nature Protocols 2006; 1 : 363-367.

9. Neves AA, Brindle KM. Assessing responses to cancer therapy using molecular imaging Biochim Biophys Acta 2006; 1766: 242-261.

10. Zhou Q, Zhao J, Stout JG, Luhm RA, Wiedmer T, Sims PJ. Molecular cloning of human plasma membrane phospholipid scramblase. A protein mediating transbilayer movement of plasma membrane phospholipids. J Biol Chem 1997; 272: 18240-18244.

11. Zhou Q, Zhao J, Wiedmer T, Sims PJ. Normal hemostasis but defective hematopoietic response to growth factors in mice deficient in phospholipid scramblase 1. Blood 2002; 99: 4030-4038.

12. Hamon $\mathrm{Y}$, Broccardo $\mathrm{C}$, Chambenoit $\mathrm{O}$, Luciani MF, Toti $\mathrm{F}$, Chaslin S et al. ABC1 promotes engulfment of apoptotic cells and transbilayer redistribution of phosphatidylserine. Nat Cell Biol 2000; 2: 399-406.

13. Darland-Ransom M, Wang X, Sun CL, Mapes J, Gengyo-Ando K, Mitani S et al. Role of C elegans TAT-1 protein in maintaining plasma membrane phosphatidylserine asymmetry. Science 2008; 320: 528-531.

14. Suzuki J, Umeda M, Sims PJ, Nagata S. Calcium-dependent phospholipid scrambling by TMEM16F. Nature 2010; 468: 834-838.

15. Mirnikjoo B, Balasubramanian K, Schroit AJ. Suicidal membrane repair regulates phosphatidylserine externalization during apoptosis. J Biol Chem 2009; 284: 22512-22516.

16. Fadeel B, Gleiss B, Hogstrand K, Chandra J, Wiedmer T, Sims PJ et al. Phosphatidylserine exposure during apoptosis is a cell-type-specific event and does not correlate with plasma membrane phospholipid scramblase expression. Biochem Biophys Res Commun 1999 266: 504-511.

17. Meng XW, Heldebrant MP, Flatten KS, Loegering DA, Dai H, Schneider PA et al. Protein kinase Cbeta modulates ligand-induced cell surface death receptor accumulation: a mechanistic basis for enzastaurin-death ligand synergy. J Biol Chem 2010; 285 888-902.

18. Vermes I, Haanen C, Steffens-Nakken H, Reutelingsperger C. A novel assay for apoptosis. Flow cytometric detection of phosphatidylserine expression on early apoptotic cells using fluorescein labelled Annexin V. J Immunol Methods 1995; 184: 39-51.

19. Meng XW, Lee SH, Dai H, Loegering D, Yu C, Flatten K et al. Mcl-1 as a buffer for proapoptotic Bcl-2 family members during TRAlL-induced apoptosis: a mechanistic basis for sorafenib (Bay 43-9006)-induced TRAlL sensitization. J Biol Chem 2007; 282 29831-29846.

20. Ding H, Hackbarth J, Schneider PA, Peterson KL, Meng XW, Dai H et al. Cytotoxicity of farnesyltransferase inhibitors in lymphoid cells mediated by MAPK pathway inhibition and Bim up-regulation. Blood 2011; 118: 4872-4881.

21. Kaufmann SH, Desnoyers S, Ottaviano Y, Davidson NE, Poirier GG. Specific proteolytic cleavage of poly(ADP-ribose) polymerase: an early marker of chemotherapy-induced apoptosis. Cancer Res 1993; 53: 3976-3985.
22. Ford MG, Pearse BM, Higgins MK, Vallis Y, Owen DJ, Gibson A et al. Simultaneous binding of Ptdlns $(4,5) P 2$ and clathrin by AP180 in the nucleation of clathrin lattices on membranes. Science 2001; 291: 1051-1055.

23. Wyllie AH, Kerr JF, Currie AR. Cell death: the significance of apoptosis. International Review of Cytology 1980; 68: 251-306.

24. Bortner CD, Cidlowski JA. Life and death of lymphocytes: a volume regulation affair. Cell Physiol Biochem 2011; 28: 1079-1088.

25. Maeno E, Ishizaki Y, Kanaseki T, Hazama A, Okada Y. Normotonic cell shrinkage because of disordered volume regulation is an early prerequisite to apoptosis. Proc Natl Acad Sci USA 2000; 97: 9487-9492

26. Frasch SC, Henson PM, Kailey JM, Richter DA, Janes MS, Fadok VA et al. Regulation of phospholipid scramblase activity during apoptosis and cell activation by protein kinase Cdelta. J Biol Chem 2000; 275: 23065-23073.

27. Williamson P, Bevers EM, Smeets EF, Comfurius P, Schlegel RA, Zwaal RF. Continuous analysis of the mechanism of activated transbilayer lipid movement in platelets. Biochemistry 1995; 34: 10448-10455.

28. McNeil PL, Kirchhausen T. An emergency response team for membrane repair. Nat Rev Mol Cell Biol 2005; 6: 499-505

29. Rodriguez A, Webster P, Ortego J, Andrews NW. Lysosomes behave as Ca2 + -regulated exocytic vesicles in fibroblasts and epithelial cells. J Cell Biol 1997; 137: 93-104.

30. Yoshida H, Kawane K, Koike M, Mori Y, Uchiyama Y, Nagata S. Phosphatidylserinedependent engulfment by macrophages of nuclei from erythroid precursor cells. Nature 2005; 437: 754-758.

31. Keerthivasan G, Small S, Liu H, Wickrema A, Crispino JD. Vesicle trafficking plays a nove role in erythroblast enucleation. Blood 2010; 116: 3331-3340.

32. Elliott JI, Sardini A, Cooper JC, Alexander DR, Davanture S, Chimini G et al. Phosphatidylserine exposure in $\mathrm{B}$ lymphocytes: a role for lipid packing. Blood 2006; 108 1611-1617.

33. Fischer K, Voelkl S, Berger J, Andreesen R, Pomorski T, Mackensen A. Antigen recognition induces phosphatidylserine exposure on the cell surface of human CD8 $+\mathrm{T}$ cells. Blood 2006; 108: 4094-4101.

34. Keller S, Konig AK, Marme F, Runz S, Wolterink S, Koensgen D et al. Systemic presence and tumor-growth promoting effect of ovarian carcinoma released exosomes. Cancer Lett 2009; 278: 73-81.

35. Luzio JP, Pryor PR, Bright NA. Lysosomes: fusion and function. Nat Rev Mol Cell Biol 2007; 8: 622-632.

36. Mellgren RL. A plasma membrane wound proteome: reversible externalization of intracellular proteins following reparable mechanical damage. J Biol Chem 2010; 285: 36597-36607.

37. Cai C, Masumiya H, Weisleder N, Matsuda N, Nishi M, Hwang M et al. MG53 nucleates assembly of cell membrane repair machinery. Nat Cell Biol 2009; 11: 56-64.

38. Leventis PA, Grinstein S. The distribution and function of phosphatidylserine in cellular membranes. Annu Rev Biophys 2010; 39: 407-427.

39. Nicoletti I, Migliorati G, Pagliacci MC, Grignani F, Riccardi C. A rapid and simple method for measuring thymocyte apoptosis by propidium iodide staining and flow cytometry. Immunol Methods 1991; 139: 271-279.

40. Walev I, Bhakdi SC, Hofmann F, Djonder N, Valeva A, Aktories K et al. Delivery of proteins into living cells by reversible membrane permeabilization with streptolysin-O. Proc Nat Acad Sci USA 2001; 98: 3185-3190.

41. Dekkers DW, Comfurius P, Bevers EM, Zwaal RF. Comparison between $\mathrm{Ca} 2+$-induced scrambling of various fluorescently labelled lipid analogues in red blood cells. Biochem $J$ 2002; 362(Pt 3): 741-747.

42. Kaufmann SH. Reutilization of immunoblots after chemiluminescent detection. Anal Biochem 2001; 296: 283-286.

43. Kaufmann SH. Induction of endonucleolytic DNA cleavage in human acute myelogenous leukemia cells by etoposide, camptothecin, and other cytotoxic anticancer drugs: a cautionary note. Cancer Res 1989; 49: 5870-5878.

\section{Supplementary Information accompanies the paper on Cell Death and Differentiation website (http://www.nature.com/cdd)}

